\title{
Antimicrobial and Mycochemical Analysis of Crude Extracts of Marine and Terrestrial Fungi
}

\author{
Neha Keral' ${ }^{1}$, Govindaiah ${ }^{2}$, M. Shivashankar ${ }^{3}$ and Manmohan \\ M.S. ${ }^{4}$
}

\author{
Department of Life Science, Jnanabharathi, Bangalore University, \\ Bengaluru - 560 056, Karnataka, India
}

\begin{abstract}
In search of new bioactive compounds against human pathogens, marine and terrestrial fungi were isolated from Puducherry coastline and Bengaluru respectively. A comparative study was done on both terrestrial and marine fungi with respect to the mycochemical analysis and antimicrobial activity against Staphylococcus aureus, Salmonella typhi, Bacillus cereus, Escherichia coli and Candida albicans. Morphologically identified selected fungi were cultured for the production of secondary metabolites in Potato Dextrose Broth medium to obtain the crude extract using ethyl acetate. Mycoconstituents revealed the presence of tannins, terpenoids, steroids, phenolics and flavanoids in marine derived fungi SW13, in SW7 only phenolics and tanins were present. Terrestial fungi SS3 showed the presence of phenolics, tanins, flavanoids whereas SS7 showed the absence of all myco-constituents. The marine derived fungi SW13 gave effective inhibition to all the tested pathogens, whereas SW7 gave effective inhibition against $S$. typhi, B. cereus and C. albicans. While, terrestrial fungi SS3 recorded inhibition against $S$. aureus, S. typhi and B. cereus. SS7 showed no antimicrobial activity against pathogens.
\end{abstract}

Keywords: Marine fungi, terrestrial fungi, comparative study, mycochemical analysis antimicrobial activity.

\section{Introduction}

Marine microorganisms comprise of an important group of secondary metabolite producers and natural products shown diverse activities such as antibacterial, antifungal, anticancer and antiviral. There had been continuous investigations carried out on marine microorganisms which proved that they are unlimited natural source of novel biologically active secondary metabolites (Hughes and Fenical, 2010). As variation of the culture media according to the OSMAC (one strain many compounds) approach, can drastically altered metabolite of the same strain which is helpful in the production of different compounds (Liu et. al., 2016). Secondary metabolites produced by marine organisms are thought to facilitate their survival and adaptation in marine environments which has special adverse conditions (Bhakuni et. al., 2005).

When it comes to terrestrial fungi, they have been exploited effectively for secondary metabolites production. It started with the discovery of Penicillin (the foremost authentic antibiotic to be used therapeutically) by Flemming's serendipity in 1926, and thereafter the search for novel biologically active natural products from terrestrial fungi started and is still going on. While the attention of finding drug from the sea started from 1970's. For instance, about 300 patents on biologically active marine natural products have been issued between 1969 \& 1999. So far, more than 10,000 compounds have been isolated from marine organisms (Jirge et. al., 2010). Though, only few new antibacterial compounds get approved by the U.S. Food \& Drug Administration. There is a huge scope for the discovery of effective new antimicrobial compounds.

The present study therefore is focused on identification of different myco-constituents of secondary metabolites produced by terrestrial and marine fungi. As the salinity is one of the main environmental factors that affect fungal growth as well as the production of secondary metabolites. In 
this work, a comparative study had been conducted on secondary metabolites of terrestrial and marine derived fungi, their myco-constituents and antimicrobial activity against some selected human pathogens.

\section{Materials and Methods}

\subsection{Isolation and Purification}

Isolation of marine derived fungi was done from sea water collected from Muthialpet coastline, Pudducherry. The water samples were collected by specific technique used by Hohnk, 1972. Fungal strains were isolated from sea water following serial dilution-pour plate method by using Artificial Sea Water (ASW), (Lyman \& Flemming, 1940). From each dilution, plating was done on PDA medium at $\mathrm{pH}-8.0$. All the plates were incubated at $27 \pm 2^{0} \mathrm{C}$ for $10-15$ days.

Terrestrial fungi were isolated from the soil samples which were collected from Bangalore University campus, Bengaluru. Isolation of fungi was done following standard serial dilution-spread plate method using PDA medium. The plates were incubated at $27 \pm 2 \mathrm{C}$ for 7-10 days (Aneja 2015).

The distinct sporulated hyphal colonies on the agar plates were then sub-cultured on sterile PDA plates using monohyphal tip method for purification (Ainsworth, 1993). The culture media plates used were supplemented with antibiotic streptomycin sulphate to avoid bacterial contamination (Samuel et. al., 2011).

\subsection{Identification}

Identification was carried by using keys, descriptions and illustrations given in standard fungal identification books. Morphological characters were observed under binocular light microscope (40x and 100x) using lactophenol cotton blue stain and identified with the help of keys given by Kohlmeyer and Kohlmeyer (1979, 1991), Barghoom \& Linder (1944), Johnson \& Sparrow (1961), Barnett \& Hunter (2000). Also by following the taxonomic arrangements proposed in the 6th edition of Ainsworth and Bisby's Dictionary of Fungi (Ainsworth, 1971).

\subsection{Fermentation}

Small inoculums' discs from well grown pure cultures of selected fungi were inoculated into conical flasks containing PDB medium. The fermentation medium of the terrestrial strains was prepared using distilled water, while for marine derived strains ASW was used. The fermentation media were incubated at $27 \pm 2^{0} \mathrm{C}$ for 14 days. (Fuhang et. al., 2012).

\subsection{Extraction}

After 14 days of fermentation, mycelia and culture broth were separated. Filtered culture broth was extracted with ethyl acetate $(1: 1 \mathrm{~V} \backslash \mathrm{V})$ thrice and mycelia were macerated using ethyl acetate in mortar and pestle, and then filtered using Whatman No.1 filter paper. The culture broth containing ethyl acetate was separated using separating funnel (Kalyani et. al., 2017) to get the crude extract for further studies.

\subsection{Mycochemical analysis}

The preliminary analyses were carried out according to Zohra et. al., 2012, Ramamurthy et. al., 2017, Thurati et. al., 2017, Shabaan et. al., 2014. The extracts obtained were subjected to various standard chemical tests to detect the mycoconstituents.

2.6. Antimicrobial assay of crude extract by Well-Diffusion method

The extracted secondary metabolites were dissolved in Dimethyl Sulfoxide (DMSO) at concentrations of $100 \mu \mathrm{g} / \mathrm{ml}$ poured into the $5 \mathrm{~mm}$ diameter well made in Petri dishes containing Nutient Agar (NA) for bacteria, Sabaroud's Dextrose Agar (SDA) for yeast. The plates were seeded with a fixed amount of test-microorganisms $\left(10^{6}\right.$ cells $\left./ \mathrm{ml}\right)$. The cultures were kept for 12 hours at $2-8^{0} \mathrm{C}$ for antimicrobial metabolite diffusion and thereafter they were incubated at an appropriate temperature for the growth of test-microorganisms. The zone of inhibition was measured in $\mathrm{mm}$ (Ramesha et. al., 2014).

Antimicrobial assay of ethyl acetate crude extract was done against two gram positive bacteria: Bacillus cereus (MTCC 497), Staphylococcus aureus (NCIM 2079), gram negative bacteria: Escherichia coli (MTCC 443), Salmonella typhimurium (NCIM 2501) and yeast: Candida albicans (MTCC 227) using $100 \mu \mathrm{g} / \mathrm{ml}$ concentration (Perez et. al., 1990). Antibiotic Ciprofloxacin was used as positive control for bacteria and Nystatin dihydrate for yeast.

\subsection{Statistical analysis}

Two way Analysis of Variance (ANOVA) has been done to determine the significance of difference between different fungal extracts and pathogens $(p<0.05)$ using SPSS-16.0. Mean values between extracts and pathogens were compared for 
significant differences using Duncan's new multiple range post-hoc test.

\section{Results and Discussions}

\subsection{Isolation and identification}

The fungi investigated in this study were predominantly isolated from soil and sea water. Some fungi which were repeating and producing spores were selected, isolated and identified by their cultural and morphological characteristic features. Thus, four repeated isolates were identified, two from soil and two from marine water for further screening. The fungi were identified as Aspergillus sp. (SW7 \& SW13) from Sea water and Penicillium sp. (SS3 \& SS7) from soil sample.

Further, molecular protocol of 16srRNA amplification and sequencing of Internal Transcribed Spacer (ITS) region is a relevant strategy for rapid taxonomic assessment of fungal strains which is useful for drug discovery need to be carried out.

\subsection{Mycochemical analysis}

In the comparative study of the mycochemcial constituents of marine derived fungi and terrestrial fungi, it has been found that marine derived fungi were rich in mycoconstituents as compared to terrestrial fungi. Both the marine derived fungal isolates were rich in phenolics and tannins, while flavanoids, terpenoids and steroids were present only in SW13 (Table-1). Whereas, in terrestrial fungi SS3, only phenolics, flavanoids and tannins were present and rest were absent. In SS7, there were no mycoconstituents found (Table-2). Alkaloids were not present in both marine and terrestrial isolates.

It has been previously found that terpenoids have been isolated as bioactive agents from marine sources. Chinworrungsee et. al., 2001 reported an ophiobolane sesterterpene named halorosellinic acid from cultured marine fungus Halorosellinia oceanica BCC 5149 which showed antibacterial activity with an $\mathrm{IC}_{50}$ value of $13 \mu \mathrm{g} / \mathrm{ml}$. Kuznetsova et. al., 2001 found out a steroid named fusidic acid in Stilbella aciculosa having antibacterial activity against $S$. aureus (MIC- $0.05 \mathrm{mg} / \mathrm{ml}$ ) and B. subtilis (MIC- $0.05 \mathrm{mg} / \mathrm{ml}$ ). Thus, increase the antibacterial activity of marine derived fungus. This shows the previous research have also stated the presence of terpenoid and steroids in marine derived fungi.
Table-1: Qualitative analysis of mycochemicals in ethyl acetate extract of marine derived fungi (SW7 \& SW13)

\begin{tabular}{|l|l|c|c|}
\hline \multirow{2}{*}{$\begin{array}{l}\text { Myco- } \\
\text { constituents }\end{array}$} & \multirow{2}{*}{ Tests Conducted } & \multicolumn{2}{c|}{ Results } \\
\cline { 2 - 4 } Alkaloids & $\begin{array}{l}\text { Mayer's } \\
\text { test }\end{array}$ & - & - \\
\hline Phenolics & $\begin{array}{l}\text { Neutral Ferric } \\
\text { chloride test }\end{array}$ & + & + \\
\hline Proteins & $\begin{array}{l}\text { Ninhydrin } \\
\text { test }\end{array}$ & - & - \\
\hline Tanins & $\begin{array}{l}\text { Ferric chloride } \\
\text { (Alcoholic) test }\end{array}$ & + & + \\
\hline $\begin{array}{l}\text { Terpenoids \& } \\
\text { Steroids }\end{array}$ & $\begin{array}{l}\text { Chloroform } \\
\text { test }\end{array}$ & - & + \\
\hline Flavanoids & Dil. NaOH test & - & + \\
\hline Note: + Present, - Absent
\end{tabular}

Table-2: Qualitative analysis of mycochemicals in ethyl acetate extract of terrestrial fungi (SS3 \& SS7)

\begin{tabular}{|l|l|c|c|}
\hline \multirow{2}{*}{$\begin{array}{c}\text { Myco- } \\
\text { constituents }\end{array}$} & \multirow{2}{*}{ Tests Conducted } & \multicolumn{2}{|c|}{ Results } \\
\cline { 3 - 4 } Alkaloids & $\begin{array}{l}\text { Mayer's } \\
\text { test }\end{array}$ & - & - \\
\hline Phenolics & $\begin{array}{l}\text { Neutral Ferric } \\
\text { chloride test }\end{array}$ & + & - \\
\hline Proteins & $\begin{array}{l}\text { Ninhydrin } \\
\text { test }\end{array}$ & - & - \\
\hline Tanins & Ferric chloride test & + & - \\
\hline $\begin{array}{l}\text { Terpenoids \& } \\
\text { Steroids }\end{array}$ & Chloroform test & - & - \\
\hline Flavanoids & Dil. NaOH test & + & - \\
\hline
\end{tabular}

In future, the preliminary work is to be proceeded with compound isolation, purification and characterization.

\subsection{Antimicrobial assay of crude extract by}

Well-Diffusion method

The crude extract of the potential fungal isolates exhibited a broad spectrum of antimicrobial activity against human pathogens when compared with that of standard positive control Ciprofloxacin for bacteria and Nystatin dehydrate for Candida albicans. According to Rios and Recio, 2005 extracts of natural origin showing antimicrobial activity above $100 \mu \mathrm{g} / \mathrm{mL}$ concentration should be avoided; therefore, in the present study, the crude extract was maintained at concentration of 100 $\mu \mathrm{g} / \mathrm{mL}$. The results showed the zone of inhibition of test pathogens ranged from $8.16 \mathrm{~mm}$ to 18.66 $\mathrm{mm}$ of tested fungal crude extracts.

Well-diffusion assay of extracts showed activity against both Gram positive and Gram negative bacteria. Among two marine derived crude extracts of Aspergillus strains SW7 and SW13, SW13 had recorded antibacterial and antifungal activity 
against all the test pathogens. As present in table-3, there was a significant difference against the activity of SW13 \& SW7 between pathogens. Between pathogens, SW13 crude extract showed highest inhibition against $S$. typhi (18.66mm) followed by $B$. cereus $(13.25 \mathrm{~mm})$ whereas it recorded minimum activity against $E$. coli $(8.16 \mathrm{~mm})$. There was no significant difference between $S$. aureus $(11.25 \mathrm{~mm})$ and albicans $(11.61 \mathrm{~mm})$. In SW7 only $S$. typhi observed maximum inhibition with $12.33 \mathrm{~mm}$, followed by $B$. cereus $(10.83 \mathrm{~mm})$ and $C$. albicans (10.50mm).

Among terrestrial fungal crude extracts of two Penicillium sp. SS3 and SS7, SS3 showed maximum inhibition for $B$. cereus $(14.66 \mathrm{~mm})$ followed by $S$. typhi $(14.33 \mathrm{~mm}), \quad S$. aureus $(11.66 \mathrm{~mm})$. Whereas, no inhibition zone was observed in E. coli and C. albicans. While, SS7 showed no antibacterial and antifungal activity.

Among all the crude extracts SW13, SW7 \& SS3, SS13 have significant difference in antimicrobial activity against all tested pathogens when compared to SW7 and SS3. It was found out that activity of crude extract SW13 was relatively similar to that of reference antibacterial agent Ciprofloxacin and antifungal agent Nystatin dihydrate. There was no activity in SS7 which could be due to the absence of important myco- constituents from the crude extracts of terrestrial fungi.

The crude extract of secondary metabolites potentially inhibited growth of human pathogeics bacteria and $C$. albicans and can diminish the growth of the harmful bacteria or fungi by their different mode of action. The present results correlated with the previous findings (Zheng et. al, 2013, Liu et. al., 2011, Chun-Yan et. al., 2013, Wang et. al., 2012) who have earlier reported antimicrobial activities of marine fungi. Aspergillus sp. has been reported as marine fungi with diverse biological activity (Saleem et. al., 2007) and it provides an opportunity to discover novel bioactive metabolites.

Wang et. al., 2011, reported three new compounds, terremides and terrelactone, along with twelve known other compounds purified and identified from the fermentation broth of Aspergillus terreus PT06-2 at $10 \%$ salinity having antibacterial and anti-H1N1 activity. This showed that high salt stress affected the quantity and profile of secondary metabolites.

While terrestrial fungi being exploited nicely which has been studied for years, marine fungi has not been explored as thoroughly. Kohlmeyer, 1979 stated that, due to salinity, the quantity and profile of secondary metabolites of fungi change in marine environment as compared to soil fungi.

Table-3: Antimicrobial activity of ethyl acetate crude extracts obtained from marine derived fungi (SW7 \& SW13) and terrestrial fungi (SS3 \& SS7)

\begin{tabular}{|c|c|c|c|c|c|c|c|}
\hline \multirow{2}{*}{ Source } & \multirow{2}{*}{$\begin{array}{c}\text { Test Fungal } \\
\text { Extracts }\end{array}$} & \multirow{2}{*}{ Code } & \multicolumn{5}{|c|}{ Antimicrobial Activity (Zone of inhibition in mm) } \\
\hline & & & E. coli & S. aureus & S. typhi & B. cereus & C. albicans \\
\hline \multirow{2}{*}{$\begin{array}{l}\text { Marine derived } \\
\text { fungi }\end{array}$} & Aspergillus sp. & SW7 & $0 \pm 0$ & $0 \pm 0$ & $12.33 \pm 1.01$ & $10.83 \pm 0.62$ & $10.50 \pm 0.50$ \\
\hline & Aspergillus sp. & SW13 & $8.16 \pm 0.52$ & $11.25 \pm 0.66$ & $18.66 \pm 1.04$ & $13.25 \pm 0.43$ & $11.61 \pm 0.78$ \\
\hline \multirow{2}{*}{$\begin{array}{l}\text { Terrestrial } \\
\text { fungi }\end{array}$} & Penicillium sp. & SS3 & $0 \pm 0$ & $11.66 \pm 0.57$ & $14.33 \pm 0.57$ & $14.66 \pm 0.57$ & $0 \pm 0$ \\
\hline & Penicillium sp. & SS7 & $0 \pm 0$ & $0 \pm 0$ & $0 \pm 0$ & $0 \pm 0$ & $0 \pm 0$ \\
\hline PC-Bacteria & Ciprofloxacin & - & $24.10 \pm 0.17$ & $27.53 \pm 0.50$ & $23.86 \pm 3.35$ & $19.66 \pm 4.72$ & - \\
\hline PC-Fungus & Nystatin dihydrate & - & - & - & - & - & $13.10 \pm 0.45$ \\
\hline
\end{tabular}




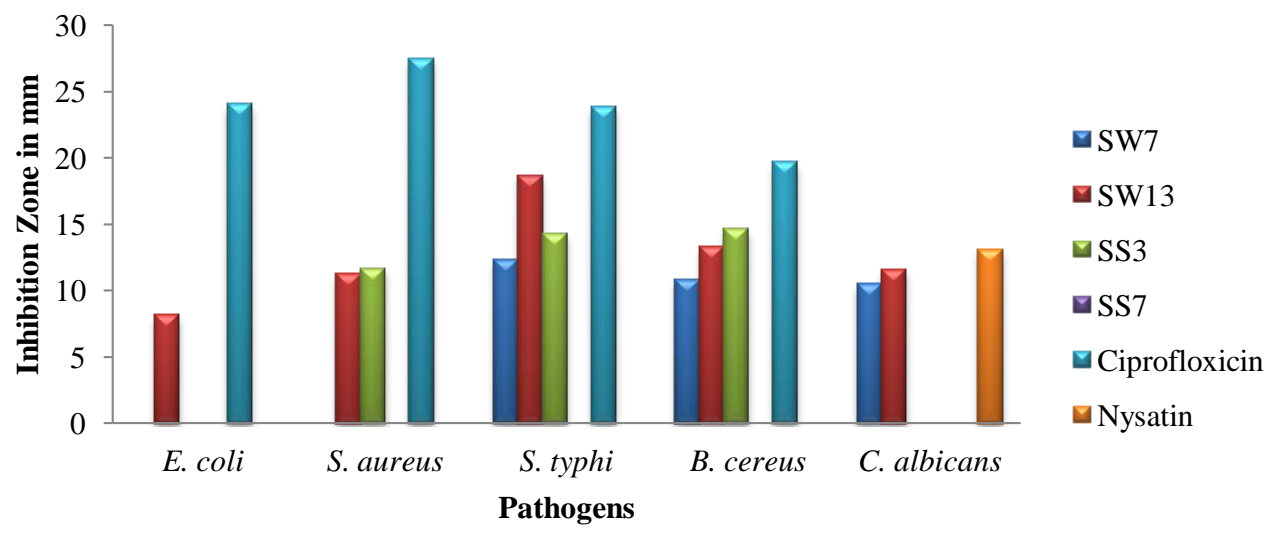

Fig-1: Antimicrobial activity of ethyl acetate crude extracts obtained from marine derived fungi (SW7 \& SW13) and terrestrial fungi (SS3 \& SS7)

\section{Conclusion}

From this comparative study, the isolated marine derived fungi showed more myco-constituents and more antimicrobial activity while terrestrial fungi showed minimum activity. The above crude extracts of marine derived fungi can be further studied for characterization, compound isolation and purification. Biological assays for anticancer, antiviral and antioxidant activities can be carried out from the bioactive compounds.

\section{References}

[1] Anisworth, G.C. Ainsworth and Bisby's Dictionary of Fungi, $6^{\text {th }}$ ed., Commonwealth Mycological Institute, Kew, Surrey, England, (1971).

[2] Aneja, K.R. Experiments in Microbiology, Plant Pathology and Biotechnology. New Age International publishers. India. pp.162-163, (2003).

[3] Ainsworth, M.A. Isolation techniques for basidiomycetes. UNESCO/WFCC Committee. 11, (1993).

[4] Barghoorn E.S., and Linder D.H. Marine Fungi: Their Taxonomy and Biology. Farlowia., 3: 395467, (1944).

[5] Barnett, H.L., and Hunter, B.B. Illustrated genera of imperfect fungi, $3^{\text {rd }}$ ed. Burgess Publishing Co., Minneapolis, Minnesota, pp.241, (1972).

[6] Bhakuni, D.S., and Rawat, D.S. Bioactive marine natural products. Springer: Rotterdam, The Netherlands, pp.382, (2005).

[7] Chinworrungesee, M., Kittakoop, M., Isaka A., Rungrod M. Tanticharoen and Thebtaranonth, Y., Bioorg. Med. Chem. Lett., pp.111-965, (2001).

[8] Chun-Yan An, Xiao-Ming Li, Chun-Shun Li, Wang Ming-Hui, Gang-Ming Xu, and Wang BinGui. Aniquinazolines A-D, four new Quinazolinone alkaloids from marine derived endophytic fungus Aspergillus nidulans. Mar. Drugs, 11: 2682-2694, (2013).

[9] Fuhang Song, Biao Ren, Ke Yu, Caixia Chen, Hui Guo, Na Yang, Hong Gao, Xueting Liu, Mei
Liu, Yaojun Tong, Huanqin Dai, Hua Bai, Jidong Wang, and Lixin Zhang. Qunazolin-4-one couled with pyrrolidin-2-iminium alkaloids from marine derived fungus Penicillium aurantiogriseum, Mar Drugs, 10: 1297-1306, (2012).

[10] Hohnk W. Fungi. In "Research Methods in Marine Biology" (C. Schlieper, ed.), Univ. of Washington Press, Seattle. pp. 142-155, (1972).

[11] Hughes, C. C., and Fenical, W. Antibacterials from the Sea. Chem. Eur. J., 16(42): 1251212525, (2010).

[12] Jirge S. S., and Chaudhari, Y. S. Marine: The ultimate Source of bioactive and Drug metabolites. IJRAP, 1(1): 55-62, (2010).

[13] Johnson, T.W., and Sparrow, F.K. Fungi in Oceans and Estuaries. J. Cramer, Weinheim, Germany, pp.668, (1961).

[14] Kalyani, P., Lakshmi, B. K. M., and Hemalatha, K. P. J. Isolation, identification of marine fungi with antibacterial activity. Int. J. Current Advanced Research, 6: 8085-8091, (2017).

[15] Kohlmeyer, J., and Kohlmeyer, E. Marine Mycology - The Higher Fungi. Academic Press; London, UK. (1979).

[16] Kohlmeyer, J., and Kohlmeyer, B. V. Bot. Mar., 34: 1-61, (1991).

[17] Kuznetsova, T.A., Smetanina O.F., Afiyatullov, S.S., Pivkin, M.V., Denisenko, V.A., and Elyakov, G.B. The identification of Fusidic acid, a steroidal antibiotic marine isolate of the fungus Stilbella aciculosa. Biochem. Syst. Ecol., 29: 873874, (2001).

[18] Liu W.C., Yang, F., Zhang R., Shi X., Lu X.H., Laun Y.S., Xiu Z.L., and Dong Y,S. Production of polyketides with antihelmintic activity by fungus Talaromyces wortmannii using one strainmany compounds (OSMAC) method. Phytochem. Lett, 18: 157-161, (2016).

[19] Liu Shaosong and Shen Yuemao. A new cyclic peptide from the marine fungal strain Aspergillus sp. AF119. Chemistry of Natural Compounds, 47(5): (2011).

[20] Lyman, J., and Fleming H.R. Composition of Sea water. J. Marine Res, 3: 134-146, (1940). 
[21] Samuel, P., Prince, L., and Prabakaran, P. Assessment of mycological diversity of marine sediment of south east coast of Tamil Nadu, India. Euro. J. Exp. Bio., 1(3): 130-138, (2011).

[22] Perez, C., Paul, M., and Bazerque, P. Antibiotic assay by agar well diffusion method. Acta. Bio. Med. Exp., 15: 113-115, (1990).

[23] Ramamurthy,V.;Sathiyadevi,M.Preliminary phytochemical screening of methanol extract of Indigofera trita. Mol. Histol. Med. Physiol., 2: 112, (2017)

[24] Ramesha, A and Srinivas, C. Antimicrobial activity and phytochemical analysis of crude extracts of endophytic fungi isolated from Plumeria acuminata L. and Plumeria obtusifolia L. Euro. J. Exp. Bio., 4(2): 35-43, (2014).

[25] Rios, J.L., Recio, M.C., Medicinal plant and antimicrobial activity. J. Ethnopharmacol., 100: 80-84, (2005).

[26] Saleem Muhammad, Ali Shaiq Muhammad, Hussain Shafqat, Jabbar Abdul, Ashraf Muhammad, Lee Yong Sup. Marine natural products of fungal origin. Nat. Prod. Rep., 24: 1142-1152. (2007).

[27] Shaaban, M., El-Metwally, M.M., Nasar, H. A new diketopiperazine alkaloid from Aspergillus oryzae. Natural Product Research: Formerly Natural Product Letters, 28: 86-94, (2014).
[28] Thurati, M., and Mishra, J.K. Antibacterial activity of crude extract from Aspergillus niger isolated from the stilt roots of Rhizophora apiculata along South Andaman coast, India. Journal of Pharmacognosy and Phytochemistry, 6:1635-1638, (2017).

[29] Wang Yi, Zheng Jinkai, Liu Peipei, Wang Wei, and Zhu Weiming. Three new compounds from Aspergillus terreus PT06-2 grown in a high salt medium. Mar. Drugs, 9: 1368-1378, (2011).

[30] Wang Rong, Liu Tian-Mi, Shen Ming-Hui, Yang Ming-Qiu, Feng Quan-Ying, Tang Xian-Ming, and Li Xiang-Min. Spiculisporic Acids B-D, three new $\gamma$-Butenolide derivatives from sea urchin derived fungus Aspergillus sp. HDf2. Molecules. 17: 13175-13182, (2012)

[31] Zheng Cai-Juan, Shao, Chang-Lun, Wu Lu-Yong, Chen Min, wang Kai-Ling, Zhao Dong-Lin, Sun Xue-Ping, Chen Guang-Ying, and Wang ChangYun. Bioactive Phenylalanine derivatives and cytochalasind from the soft coral-derived fungus, Aspergillus elegans. Mar. Drugs, 11: 2054-2068, (2013).

[32] Zohra, S.F., Meriem, B., and Samira, S. Phytochemical screening and identification of some compounds from mallow. Nat. Prod. Plant Resour, $\quad 2$ : 512-516, (2012). 